\title{
Italian adaptation of the Multilingual Assessment Instrument for Narratives
}

\author{
Chiara Levorato
}

University of Padova

\author{
Maja Roch \\ University of Padova
}

This paper presents the Italian version of the Multilingual Assessment tool for Narratives (MAIN), describes how it was developed and reports on some recent uses of MAIN within the Italian context. The Italian MAIN has been used in different research projects and for clinical purposes; results have been presented at conferences and in peer reviewed papers. The results indicate that MAIN is an appropriate assessment tool for evaluating children's narrative competence, in production and comprehension from preschool age (5 years) to school age (8 years) in typical language development, bilingual development and language delay/disorders.

\section{Importance of narrative assessment in the Italian Context}

The study and the assessment of the narrative competence and its development, in particular during the preschool age, is important for several reasons. First, as narratives are pervasive in children's everyday life, they represent the foundation for building world knowledge (Bruner, 1988). Second, narrative competence is related to further development of literacy and school achievement (Bonifacci, 2018; Florit \& Levorato, 2015). Third, for researchers, narratives are adequate to get rich information on the language proficiency of children. In fact, when children produce narratives, they have to integrate in a single output - the story - information originating from different language systems. For these reasons, clinicians and researchers consider the analysis of narrative competence an ecologically effective tool to investigate communication competence in children (Iluz-Cohen \& Walters, 2012; Pearson, 2002; Squires et al., 2014).

To date, research on the development of narrative competence in Italy has focused mainly on monolingual children (Lever \& Sénéchal, 2011; Silva, Strasser \& Cain, 2014) and only recently the focus has included bilingual children (Roch \& Florit, 2013; Roch, Florit \& 
Levorato, 2016). The research on the development of narrative competence, which is important for the reasons outlined above, is of particular importance in the field of bilingualism, as it allows to analyse the linguistic development of the bilingual child in both languages and the relationship between them (Pearson, 2002; Roch, Florit \& Levorato 2018). Our effort in the last 10 years has been to contribute to the development and adaptation of the MAIN tool in order to be used in the Italian context, both for research and clinical purposes (Roch, 2017).

\section{Developing MAIN for Italian}

The Multilingual Assessment Instrument for Narratives (MAIN, Gagarina et al., 2012; 2015) was developed within the Narrative and Discourse Working Group (WG2) of the COST Action IS0804, "Language Impairment in a Multilingual Society: Linguistic Patterns and the Road to Assessment". MAIN is part of the battery of tests known as the Language Impairment Testing in Multilingual Settings (LITMUS) battery, which have been developed within the same COST Action. We were members of the Working Group during and after the COST Action. We worked with other members under the leadership of a core group to develop materials and pilot-test MAIN versions in other languages. When MAIN was first published, it was released in 26 language versions, including Italian (see Gagarina et al., 2012).

The Italian version of MAIN has been adapted from the English version. The Italian team worked on the adaptation of the MAIN instrument taking into consideration the linguistic properties of instructions, questions, and answers and comparing the Italian with the English versions. This was done in order to obtain an Italian version parallel to the English one, in terms of performance. The focus was both on cross-cultural, conceptual but also on linguistic equivalence. In order to reach this goal, we used a well-established method: forward and backward translation.

The first Italian MAIN manual included results of 62 Italian-English bilingual children, aged between 5 and 7 years. These results were reported at COST meetings and workshops and it was published in an international peer reviewed journal (Roch, Florit \& Levorato, 2016). An updated version of the English MAIN and the manual for its use was released in 2019 (Gagarina et al., 2019). It includes various changes, correction of minor errors and clarifications in some instructions and tables. This was the base for a new Italian version, which is published along with this paper.

\section{$3 \quad$ Using MAIN in Italy}

Since it was developed in 2012, the Italian version of MAIN has been used in several research projects that mainly involve bilingual children living in the Italian speaking context, aged between 5 and 8 years. So far, we have collected about 160 narratives in different projects. 
Some of these studies have been published, others have been accepted by research journals, and still others are being drafted for submission.

Moreover, the tool has been disseminated through training courses, to operators, mainly psychologists, linguists and speech therapists. Additionally, the tool has been presented in a recent publication, an Italian manual focusing on the linguistic development of bilingual children (Levorato \& Marini, 2019, and in particular Roch \& Dicataldo, 2019; Roch, Florit \& Levorato, 2018). As a result of this dissemination, speech therapists increasingly request to use the tool in clinical settings. They report that the tool is appropriate for assessing the narrative skills of preschool and school children, both monolingual and bilingual, with atypical and/ delayed linguistic development.

\subsection{Using the Italian MAIN: general results}

In recent years, the Italian MAIN has been used in several projects, some of which have been completed, while others are still ongoing. Some of these works have been published, and therefore are available to the scientific community (see Roch, Florit \& Levorato, 2016; Roch \& Hrzica, in press; Hrzica \& Roch, in press), other works have been presented at relevant national and international conferences, whereas others have not yet been published. Below we provide a summary of the results obtained to date, integrating all the projects that have involved the Italian MAIN.

Within the age range of the participants included in our projects, i.e. between 5 and 8 years of age, we observed an important change in linguistic development, which concerns the increasing ability to produce more and more complex narratives; at the same time, narrative comprehension gradually becomes deeper.

As for the production of narratives, preschoolers tend to produce short stories, in which they connect two events, but often omit events relevant to the understanding of the story. In addition, they often produce stories in the wrong sequence. In the transition to primary school, children tend to construct stories in the correct sequence from a temporal point of view, although the stories are often incomplete. In the early years of primary school, children sharpen their ability to produce stories and tend to produce well-structured stories according to the story grammar and the events narrated tend to be linked by temporal and causal connections.

This developmental trajectory sees the inclusion of a greater number of elements within the texts produced (the stories are longer), so at the time of entering the primary school at age 6 the child is able to narrate a sequence of actions and events and knows how to use appropriate language from a lexical and morphosyntactic point of view to produce them. Moreover, in parallel with the development of the ability to tell a story following pictured stories, the ability to include elements concerning the internal states of the narrative characters develops, starting from pre-school age. At this age children begin to include in their stories references to the perceptions, emotions, thoughts and desires of the characters. Towards the age of 5 , in parallel with the development of the theory of the mind, the sequences of events in the story are narrated according to the purpose to which they are directed and explanations 
are given about the characters' motivations. The ability to make judgements about the characters' motivations and psychological characteristics is further developed during school age.

To sum up, the results achieved so far though the use of the Italian MAIN indicated that, when they develop, children tend to include a greater number of events, mental states, but especially with age they tend to increase the complexity and coherence of the narratives they produce. Stories produced by older children include more temporal and causal relationships between events than those of younger children and focus more on the internal states of the characters and their motivations.

As far as the comprehension of pictured narratives is concerned, the results of our work show that the understanding of stories generally improves with age, but above all, it becomes deeper: in fact, in the transition from preschool to school age there is a better understanding of the goals and motivations of the characters, and only after the age of 7 , the understanding of the internal states of the characters is adequate.

\subsection{Using the Italian MAIN with bilinguals}

There are different tasks within the Italian context that are used to test narrative competence, among which are telling and retelling. To our knowledge, at the moment, MAIN is the only tool available for the evaluation of the bilingual child in both languages, and with different tasks. Our data collected so far, both published (see Roch, Florit \& Levorato, 2016; Roch \& Hrzica, in press; Hrzica \& Roch, in press) and unpublished, suggest that MAIN is appropriate for the evaluation of bilinguals aged between 4 and 8 years, both for the measures of microand macrostructure. Our work has involved several groups of children from very different multilingual families. We have bilingual Italian-English children who acquire L2 (English) in the school context while using L1 (Italian) in the context of everyday life; we have immigrant children of different origins (Arabs, Albanians, Moroccans, Romanians, Moldovans, Nigerians) who live in Italy, and acquire Italian as L2; we have Croatian children (L1) who acquire Italian as L2 coming from a multicultural Croatian context on the border between Croatia and Italy; we have children from the Serbian community who live in Italy and acquire Italian as L2.

We learned from our work that the most significant advantage of MAIN is that it enables also the evaluation of the relationship - similarities and differences - between the child's performance in two languages.

Our data suggest that pre-school age bilinguals show an inconsistent and independent development of narrative competence in the two languages, while school age children, thanks to the transfer mechanism, tend to have a similar narrative competence in the two languages. Indeed, in the early stages of L2 acquisition, bilingual children show better narrative competence in their dominant language. In contrast, later on, mainly due to the intervention of literacy, which generally occurs in L2, narrative competence in L2 tends to mature faster than in L1. 
With regard to the microstructure elements, which are strongly influenced by the quantity and quality of exposure and the specific language spoken by the child, crosslinguistic transfer occurs later.

Our results indicate that the differences between the two languages concerning the macrostructure are reduced earlier than the differences in the microstructure. It has been pointed out in the literature that even children with limited competence in one of the two languages are able to produce, in the less dominant language, stories with an adequate narrative structure and a good overall quality of the story at the macrostructure level (Bonifacci et al., 2018). Our data seem to go in this direction.

\subsection{Telling vs. retelling}

The Italian MAIN has been used both in the Telling and the Retelling modes. To this date, we have no data available on the Model story mode. Our data collected so far, both published (see Roch, Florit \& Levorato, 2016; Roch \& Hrzica, in press; Hrzica \& Roch, in press) and unpublished, indicate that both the stories adopted for telling (Baby Birds, Baby Goats) and the stories adopted for retelling (Cat, Dog) seemed appropriate for the evaluation of narrative skills in the age range between 5 and 8 years.

Our recommendation is to choose the telling or retelling test depending on the purpose of the assessment, i.e. what you want to measure in the language sample obtained. In particular, retelling, compared to telling, allows to elicit longer narrative productions, with a higher number of words. If the child's production takes up the model proposed by the evaluator, there is an indication that the child is able to reconstruct a story model and therefore that the story has been understood, that a coherent semantic representation has been constructed and that the child is able to narrate it in turn. Retelling results are? seem to be? particularly useful for evaluating the macrostructure, i.e. it is useful in those cases where it is less relevant to evaluate the linguistic aspects (microstructure) but rather the ability to establish temporal and causal links in the construction of a cohesive and coherent narrative structure. For this reason, we recommend to use retelling when assessing younger children, preschoolers, children who may have language difficulties at the microstructure level but not at the macrostructure level, such as children with primary language impairment or bilingual children.

The telling, on the other hand, elicits shorter stories, but provides a pure measure of the extent to which the child is able to express a discourse in a linguistic form: in this case the child is called to construct the semantic representation and to narrate it. Our preliminary data suggest that this test is particularly useful to evaluate both the microstructure and the macrostructure and their integration. Although telling might elicit a purer measure of narrative production than retelling, it may prove to be less informative for the assessment of narrative skills of children of pre-school age, younger than 5 years of age, or who might have language difficulties at any level. In these cases, the narratives are extremely short and not very articulated, but this could be linked not so much to the narrative abilities per se but rather to the difficulty of the task, which involves an extremely high cognitive load. Therefore, we 
believe that the telling task is appropriate in assessing children's ability to integrate the various levels of linguistic processing, when they have reached a certain level of linguistic maturity.

\subsection{Using the Italian MAIN in clinical settings}

Thanks to the dissemination of the Italian version of MAIN in the last few years, we have acquired preliminary data concerning the use of this tool in the clinical setting. Clinicians and speech therapists report that the MAIN appears to be a valid and reliable tool to obtain information on different domains of the bilingual linguistic competence ranging from his or her ability to structure sentences to the ability to choose a proper vocabulary to express concepts; above all, even when these linguistic components are weak in the bilingual child, the analysis of the narrative competence through MAIN gives information on the child's ability to tell a story following the general story structure, thus revealing relevant information related to the communicative competence of the child. Therefore, there are some preliminary indications that the analysis of narrative competence with the MAIN can provide crucial information about the child's ability to integrate different levels of linguistic processing.

The preliminary results reported here need to be confirmed by in-depth analyses, but we believe that the assessment of narrative competence with the MAIN in clinical settings may help the clinician to disentangle the reasons for possible delays in the development of the bilingual language skills. It is our opinion that the assessment of narrative competence through the MAIN can be a valuable ecological tool that could be integrated into the assessment through standardised tools. These sometimes tend to underestimate real language skills. The assessment of narrative skills allows to obtain more complete information providing some useful indications to differentiate bilingual children with a typical profile from bilingual children at risk of language or learning difficulties/disorders.

\section{Conclusions}

The evaluation of narrative competence through the MAIN in Italy has proved to be a useful assessment tool both in research and clinical setting. On the other hand, the evaluation of narrative productions requires a coding of the linguistic sample and a particularly laborious and time-consuming scoring and interpretation.

The advantages are more numerous than the limitations. First, the evaluation of narrative production gives information on expressive language skills at different levels of language processing with a single test. In addition, it allows the evaluation of spontaneous production, where the child chooses what to say and how to say it. The assessment of narrative production is probably the most ecological tool to measure the child's authentic language skills and is most closely related to the language skills used in everyday life. Therefore, beyond the measure of the different indicators of microstructure and 
macrostructure, the narrative production by the child can offer an indication of his or her ability to use language for certain purposes and in certain contexts.

In conclusion, narratives are an important part of a child's linguistic development and represent one of the privileged modes of communication from early childhood. Narratives offer a complex communicative model and the analysis of narrative competence, with a valid tool such as MAIN, makes it possible to obtain multiple information concerning different levels of linguistic processing and their integration.

\section{$5 \quad$ References}

Bonifacci P. (2018). I bambini bilingui. Favorire gli apprendimenti nelle classi multiculturali. [Bilingual children. Promoting learning in multicultural classes]. Roma: Carocci.

Bonifacci P., Barbieri, M., Tomassini, M. \& Roch, M. (2018). In few words: Linguistic gap but adequate narrative structure in preschool bilingual children. Journal of Child Language, 45(1), 120-147.

Bruner J.S. (1988). La mente a più dimensioni [The multidimensional mind]. Roma-Bari: Laterza.

Florit E. \& Levorato M.C. (2015). Imparare a comprendere e produrre testi. [Learn to comprehend and produce texts]. In S. D’Amico \& A. Devescovi (Eds.), Psicologia dello sviluppo del linguaggio, Bologna: il Mulino.

Gagarina N., Klop D., Kunnari S., Tantele K., Valimaa T., Balciuniene I., Bohnacker, U., \& Walters, J. (2012). MAIN: Multilingual Assessment Instrument for Narratives. ZAS Papers in Linguistics, 56.

Gagarina, N., Klop, D., Kunnari, S., Tantele, K., Välimaa, T., Balčiūnienè, I., Bohnacker, U. \& Walters, J. (2015). Assessment of narrative abilities in bilingual children. In: S. Armon-Lotem, J. de Jong, \& N. Meir (Eds.), Assessing multilingual children: disentangling bilingualism from language impairment (pp. 243-269). Bristol: Multilingual Matters.

Gagarina, N., Klop, D., Kunnari, S., Tantele, K., Välimaa, T., Bohnacker, U. \& Walters, J. (2019). MAIN: Multilingual Assessment Instrument for Narratives - Revised. ZAS Papers in Linguistics, 63, 1-36.

Hržica, G., \& Roch, M. (in press). Lexical diversity in bilingual speakers of Croatian and Italian. In: S. ArmonLotem \& K. Grohmann (Eds.), LITMUS in Action: Cross comparison studies across Europe. Amsterdam: John Benjamins.

Iluz-Cohen, P., \& Walters, J. (2012). Telling stories in two languages: Narratives of preschool children with typical and impaired language. Bilingualism: Language and Cognition, 15(1), 58-74.

Lever, R., \& Sénéchal, M. (2011), Discussing stories: On how a dialogic reading intervention improves kindergartners' oral narrative construction. Journal of Experimental Child Psychology, 108(1), 1-24.

Levorato, M.C. \& Marini, A. (2019). Il bilinguismo in età evolutiva. [Bilingualism in the developing age]. Trento: Erikson.

Pearson B.Z. (2002). Narrative competence among monolingual and bilingual school children In: D.K. Oller \& R.E. Eilers (Eds.), Language and literacy in bilingual children (pp. 135-174), Clevedon: Multilingual Matters.

Roch, M. (2017). Potenziare le competenze linguistiche dei bambini bilingui, [Enhancing the language skills of bilingual children]. Logopedia e Comunicazione, 13(2), 281-291. 
Roch, M. \& Dicataldo, R. (2019). La competenza narrativa in bambini bilingui. [Narrative competence in bilingual children]. In M.C. Levorato \& A. Marini (Eds.), Il bilinguismo in età evolutiva (pp. 97-110). Trento: Erikson.

Roch, M. \& Florit, E. (2013). Narratives in preschool bilingual children: The role of exposure. Rivista di Psicolinguistica Applicata, 13(2), 55-63.

Roch, M., Florit, E. \& Levorato, M.C. (2016), Narrative competence of Italian-English bilingual children between 5 and 7 years. Applied psycholinguistics, 37(1), 49-67.

Roch M., Florit, E. \& Levorato, M.C. (2018). Valutare le competenze linguistiche. [Assessing the language skills]. In: S. Bonichini \& U. Moscardino (Eds.), La valutazione psicologica del bambino. Roma: Carocci.

Roch, M., \& Hržica, G. (in press). Narrative comprehension by Croatian-Italian bilingual children 5-7 years old: the role of receptive vocabulary and sentence comprehension. In: U. Bohnacker \& N. Gagarina (Eds.), Developing narrative comprehension: Multilingual Assessment Instrument for Narratives. Amsterdam: John Benjamins.

Silva, M., Strasser, K. \& Cain, K. (2014). Early narrative skills in Chilean preschool: Questions scaffold the production of coherent narratives. Early Childhood Research Quarterly, 29(2), 205-213.

Squires, K.E., Lugo-Neris, M.J, Peña, E.D., Bedore, L.M., Bohman, T.M. \& Gilliam, R.B. (2014). Story retelling by bilingual children with language impairments and typically developing controls. International Journal of Language and Communication Disorders, 49(1), 60-74. 